\title{
Male Obesity-related Secondary Hypogonadism - Pathophysiology, Clinical Implications and Management
}

\author{
Cornelius J Fernandez, ${ }^{1}$ Elias C Chacko, ${ }^{2}$ Joseph M Pappachan ${ }^{3}$
}

1. Department of Endocrinology \& Metabolism, Pilgrim Hospital, United Lincolnshire Hospitals NHS Trust, Boston, UK; 2. Department of Endocrinology, Jersey General Hospital, St Helier, Jersey; 3. Department of Endocrinology \& Metabolism, Lancashire Teaching Hospitals NHS Foundation Trust, Preston, UK

$\mathrm{T}$ he single most significant risk factor for testosterone deficiency in men is obesity. The pathophysiological mechanisms involved in male obesity-related secondary hypogonadism are highly complex. Obesity-induced increase in levels of leptin, insulin, proinflammatory cytokines and oestrogen can cause a functional hypogonadotrophic hypogonadism with the defect present at the level of the hypothalamic gonadotrophin-releasing hormone (GnRH) neurons. The resulting hypogonadism by itself can worsen obesity, creating a selfperpetuating cycle. Obesity-induced hypogonadism is reversible with substantial weight loss. Lifestyle-measures form the cornerstone of management as they can potentially improve androgen deficiency symptoms irrespective of their effect on testosterone levels. In selected patients, bariatric surgery can reverse the obesity-induced hypogonadism. If these measures fail to relieve symptoms and to normalise testosterone levels, in appropriately selected men, testosterone replacement therapy could be started. Aromatase inhibitors and selective oestrogen receptor modulators are not recommended due to lack of consistent clinical trial-based evidence.

\section{Keywords}

Obesity, male obesity-related secondary hypogonadism, testosterone replacement therapy

Disclosures: Cornelius J Fernandez, Elias C

Chacko and Joseph M Pappachan have nothing

to declare in relation to this article.

Review Process: Double-blind peer review.

Compliance with Ethics: This article involves a review of literature and does not report on new clinical data, or any studies with human or animal subjects performed by any of the authors.

Authorship: All named authors meet the criteria of the International Committee of Medical Journal Editors for authorship for this manuscript, take responsibility for the integrity of the work as a whole and have given final approval for the version to be published.

Received: 25 June 2019

Accepted: 4 July 2019

Citation: European Endocrinology. 2019;15(2):83-90

Corresponding Author: Joseph M Pappachan, Department of Endocrinology \& Metabolism, Lancashire Teaching Hospitals NHS Foundation Trust, Preston, PR2 9HT, United Kingdom. E: drpappachan@yahoo.co.in

Funding support: No funding was received in the publication of this article.
The global prevalence of obesity has increased tremendously in recent years. According to the World Health Organization, 39\% of adults were overweight, of which 13\% were obese, in 2016. 'The association between excess body weight and several medical conditions that increase morbidity and mortality is well-known.

Recent clinical evidence suggests that obesity is one of the most important risk factors for secondary hypogonadism in men. ${ }^{2-4}$ Although the actual prevalence of male obesity-related secondary hypogonadism (MOSH) is still unclear, large-scale epidemiological studies, and small population-based surveys suggest prevalence rates as high as $45.0-57.5 \% .45$ This very high reported prevalence may be an overestimate of MOSH arising from several factors, such as inaccuracies in the methods used to estimate androgen level. It may also be the assessment of clinical features, such as erectile function and libido that can be associated with marked subjective variations in the study populations. Male hypogonadism has been shown to be associated with excess morbidity and mortality in multiple clinical studies. ${ }^{6-9}$ Therefore, we aim to discuss the pathophysiology, clinical aspects, diagnostic approach and management options for patients with MOSH in this comprehensive review.

\section{Pathophysiology of male obesity-related secondary hypogonadism \\ Obesity and hypogonadism - bidirectional relationship}

There is a bidirectional relationship between obesity and hypogonadism. ${ }^{10}$ In population-based studies, obesity is the single most important factor resulting in testosterone deficiency." Similarly, testosterone deficiency can cause increased adipogenesis and visceral obesity as evidenced by rapid weight gain observed in men following androgen deprivation therapy or surgical castration. ${ }^{12-14}$ Testosterone deficiency is associated with visceral fat dysfunction, subsequent chronic inflammation, insulin resistance and low sex hormone binding globulin (SHBG) levels. ${ }^{15,16}$ Weight loss achieved pharmacologically with liraglutide ${ }^{17}$ or with bariatric surgery improved testosterone and gonadotrophin levels, and were able to reverse the hypogonadotrophic hypogonadism caused by obesity. ${ }^{18-20}$

Metabolic syndrome and hypogonadism - bidirectional relationship As is the case with obesity and hypogonadism, there is also a bidirectional relationship between metabolic syndrome and testosterone deficiency. Metabolic syndrome is associated with testosterone deficiency and low SHBG. ${ }^{21}$ The higher the number of metabolic syndrome components, the lower the testosterone levels will be. ${ }^{22}$ However, low free testosterone (FT) levels 
are not consistently associated with metabolic syndrome risk. ${ }^{21}$ Two recent studies in hypogonadal men, in which the association between total testosterone (TT) and metabolic syndrome were adjusted for SHBG, concluded that it is not total testosterone, but SHBG that is independently associated with metabolic syndrome risk. ${ }^{23,24}$

\section{Hypogonadal-obesity hypothesis}

Pathophysiological mechanisms for hypogonadism in obesity and for obesity in testosterone deficiency are complex and multifactorial. Individuals with MOSH exhibited a normal luteinising hormone $(\mathrm{LH})$ and follicle stimulating hormone (FSH) response to gonadotropin releasing hormone $(\mathrm{GnRH})$ indicating a hypothalamic defect rather than a pituitary defect. ${ }^{25}$ There is a bidirectional relationship between total testosterone level and amount of visceral adipose tissue, as proposed by Cohen in the hypogonadal-obesity hypothesis. ${ }^{26}$ Obese men with metabolic syndrome are at increased risk of developing testosterone deficiency. ${ }^{27}$

\section{Hypogonadal-obesity-adipocytokine hypothesis}

The hypogonadal-obesity-adipocytokine hypothesis is an extension of Cohen's theory, which explains why the body cannot produce compensatory testosterone via increased gonadotrophin secretion and subsequent stimulation of the Leydig cells. In obese individuals, enhanced aromatase enzymes produced by adipose tissue reduce the testosterone and increase the oestrogen hormones. Testosterone deficiency facilitates further adipocyte differentiation, adipocyte inflammation and insulin resistance. The resultant increase in oestrogen, leptin, insulin and inflammatory cytokines result in hypothalamo-pituitary-testicular (HPT) axis suppression. ${ }^{28}$

\section{Testosterone-oestradiol shunt}

Obesity increases the expression of aromatase enzyme (CYP19A1) in the adipocytes, which enhances the conversion of androstenedione and testosterone to oestrone (E1) and oestradiol (E2) respectively. The resultant reduction in circulating testosterone level leads to further adipocyte hypertrophy and further worsening of testosterone deficiency. The increased oestrogens formed from aromatisation causes a negative feedback at hypothalamo-pituitary level, further lowering testosterone levels. ${ }^{28}$

\section{Adipocyte hypertrophy and dysfunction}

Lipoprotein lipase present on the extracellular surface of adipocytes hydrolyses circulating triglyceride-rich lipoproteins to free fatty acids which are taken up by the adipocytes and then esterified back into triglycerides for storage. Testosterone reduces the lipoprotein lipase activity in adipose tissue and inhibits the triglyceride storage. Testosterone deficiency is associated with enhanced triglyceride storage and subsequent increase in total body fat. ${ }^{28}$

Catecholamines are the major hormones controlling lipolysis in adipose tissue, acting via the adrenoreceptors. Testosterone upregulates the beta-adrenoreceptor number; activates adenyl cyclase to produce cyclic adenosine monophosphate which, in turn, stimulates hormone-sensitive lipase to accelerate lipolysis; and decreases total body fat mass. ${ }^{28}$

Androgen receptors are present in adipose tissue, the density of which is positively regulated by testosterone. Testosterone can decrease adipogenesis via a direct androgen-receptor-dependent mechanism. Incubation of isolated pluripotent stem cells with testosterone stimulated the development of cells of myogenic lineage rather than adipogenic lineage through an androgen-receptor-dependent mechanism, providing a molecular explanation for the decreases in fat mass and increases in lean mass observed after testosterone therapy. ${ }^{29}$

\section{Proinflammatory cytokines}

Testosterone exerts an anti-inflammatory effect as it prevents adipocyte hypertrophy and dysfunction. Testosterone and its aromatisation product, oestradiol, activate androgen receptors (AR) and estrogen receptors (ER $\alpha$ and $E R \beta$ ) within the visceral adipose tissue, with a resultant decrease in the release of adipokines (leptin, tumor necrosis factor alpha [TNF- $\alpha$ ], interleukin-6 [IL-6], osteoprotegerin, monocyte chemoattractant protein-1 $\alpha$ ) and increase in the release of adiponectin and visfatin. Testosterone improves insulin sensitivity and reduces the c-reactive protein from the liver. ${ }^{30}$ During testosterone deficiency, which is a proinflammatory state, the increased fat mass leads to adipocyte dysfunction, resulting in a decrease in adiponectin and an increase in adipokines such as leptin, IL-1, IL-6, and TNF- $\alpha$ secreted from both adipocytes and activated macrophages. ${ }^{31}$ These adipokines further worsen the inflammation and induce a state of systemic insulin resistance. ${ }^{32}$ Moreover, adipokines cause hypogonadism by impairing kisspeptin signalling to reduce GnRH secretion. ${ }^{33,34}$

\section{Insulin resistance}

Insulin resistance in testosterone deficiency is mediated by body composition dependent effects, including increased adipocyte differentiation (visceral obesity) and decreased myocyte differentiation (sarcopenia), and body composition independent effects such as increased inflammation (TNF- $\alpha$, IL-1 and IL-6), decreased adiponectin and reduced mitochondrial function. ${ }^{35,36}$ Resultant hyperinsulinaemia acts on the kisspeptin neurons to decrease kisspeptin signalling, which, in turn, acts on the GnRH neurons to decrease GnRH release and thereby LH secretion. ${ }^{37}$

\section{Leptin resistance}

In normal physiological conditions, leptin acts through kisspeptin neurons to stimulate GnRH and thereby LH secretion..$^{38}$ Testosterone suppresses leptin secretion from adipose tissue. In obesity induced adipocyte dysfunction, there is increased leptin release from adipocytes, which, in turn, causes a central leptin resistance at the hypothalamopituitary level. This decreases hypothalamic kisspeptin gene expression, which subsequently decreases GnRH and LH secretion and worsens testosterone deficiency. ${ }^{39,40}$ Moreover, leptin directly inhibits the stimulatory effects of gonadotrophins on the Leydig cells to further decrease testosterone secretion, via peripheral leptin resistance. ${ }^{41,42}$

\section{Final common pathway of $\mathrm{GnRH}$ regulation}

Kisspeptin neurons are located in the infundibular nucleus and GnRH neurons are situated in the preoptic area of the hypothalamus. ${ }^{37}$ Kisspeptin regulates the HPT-axis by stimulation of its receptor on GnRH neurons, thereby regulating $\mathrm{LH}$ and FSH secretion. ${ }^{43} \mathrm{GnRH}$ neurons express kisspeptin receptors (KISS1R), but do not express receptors for leptin and insulin, whereas kisspeptin neurons have receptors for leptin, insulin and oestrogen. ${ }^{38,40,44}$ The central regulation of testosterone production in normal individuals is shown in Figure $1 \mathrm{~A}$ and that in MOSH is shown in Figure $1 B$.

\section{Metabolic endotoxaemia}

The human gut contains more than 100 trillion bacteria and approximately $70 \%$ of these are gram negative, containing lipopolysaccharide. ${ }^{45}$ Normally these bacterial endotoxins are prevented from entering circulation by the intestinal mucosal barrier. A recently proposed GELDING (Gut Endotoxin Leading to a Decline IN Gonadal function) theory suggests that high-calorie, high-fat diet breaks down integrity of this mucosal barrier and results in metabolic endotoxaemia, a pro-inflammatory state, and consequential hypogonadism. ${ }^{45}$ 
Figure 1: The central regulation of testosterone production in normal individuals and individuals with male obesity-related secondary hypogonadism

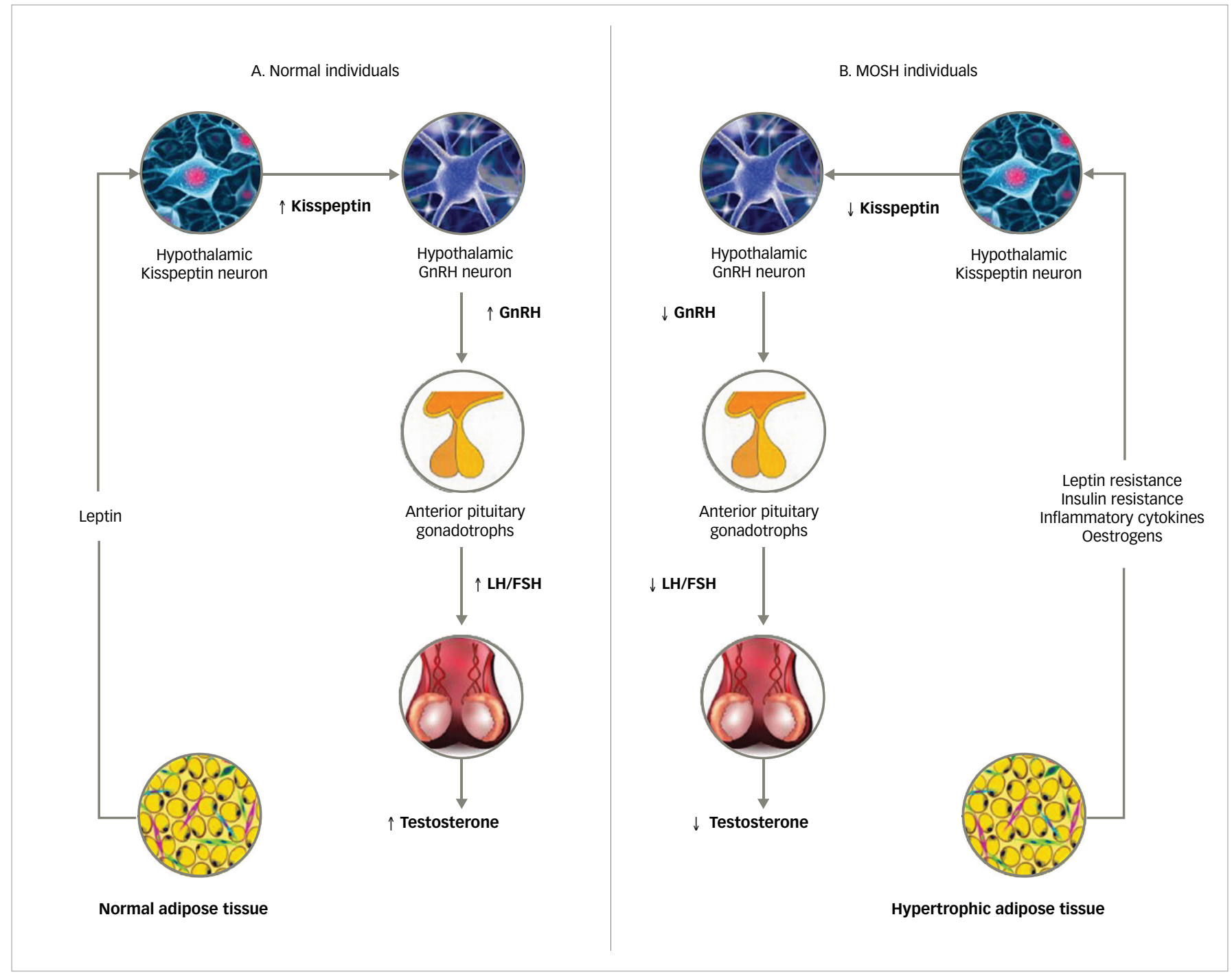

FSH = follicle stimulating hormone; GNRH = gonadotropin releasing hormone; $\mathrm{LH}=$ luteinising hormone; MOSH = male obesity-related secondary hypogonadism

Obesity and sex hormone binding globulin

Most of the SHBG in circulation is produced in the liver. Low SHBG levels seen in obesity is caused by the high lipid content of the liver and by high pro-inflammatory cytokines (TNF- $\alpha$ and IL-1) rather than by hyperinsulinaemia (insulin resistance) as was previously thought. ${ }^{46}$ Though SHBG functions primarily as a transporter of sex steroids, it has additional actions. SHBG has anti-inflammatory effects. It decreases fat content in macrophages and adipocytes and suppresses inflammation. Low SHBG can be the result of insulin resistance. ${ }^{47}$

\section{Obstructive sleep apnoea and hypogonadism}

There is a bidirectional relationship between testosterone deficiency and obstructive sleep apnoea (OSA). Patients with OSA have reduced rapid eye movement (REM) sleep duration, reduced deep sleep duration, and reduced sleep efficiency associated with increased night-time awakenings, sleep fragmentation and nocturnal hypoxia, all of which leads to a low testosterone level. Similarly, low testosterone promotes obesity, decreases REM sleep and deep sleep, thus negatively affecting sleep quality. ${ }^{48}$

The pathophysiological aspects of MOSH are summarised in Figure 2.

\section{Clinical presentation}

Men with functional hypogonadism commonly present with non-specific symptoms and modestly low testosterone levels. In the European Male Ageing Study (EMAS), only three out of 32 sexual symptoms were syndromically associated with testosterone deficiency. ${ }^{49}$ Only $0.6 \%$ of healthy men or $0.4 \%$ of lean men developed functional hypogonadism which implies that functional hypogonadism usually develops in obese men with comorbidities.

\section{Diagnostic approach}

MOSH can be diagnosed when all of the following features are present:2

1. Obese male with body mass index (BMI) of $\geq 30 \mathrm{~kg} / \mathrm{m}^{2}$.

2. Clinical hypogonadism: impaired sexual, physical or mental performance, impaired sexual characteristics, gynaecomastia, breast pain, sleep problems, dysglycaemia, flushing, low bone mineral density (BMD) or unexplained anaemia.

3. Biochemical hypogonadism: morning $\pi \mathrm{T}$ less than the lower limit for healthy young men as measured using a reliable assay, confirmed twice, or in the presence of abnormal SHBG, FT or bioavailable testosterone less than lower limit for healthy young men in a reliable assay. 
Figure 2: The pathophysiological aspects of male obesity-related secondary hypogonadism

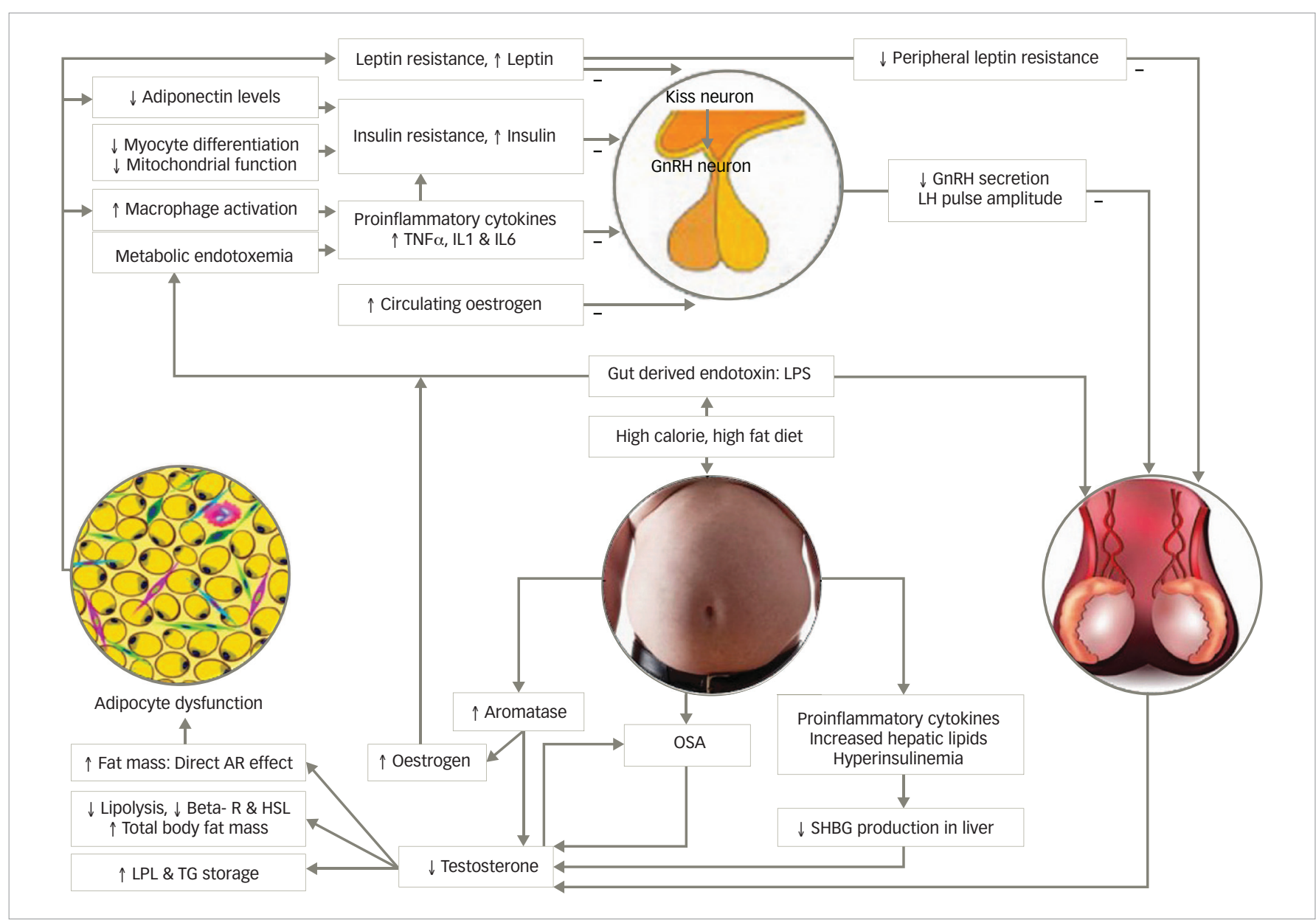

$A R=$ androgen receptor; Beta- $R=$ beta adrenoreceptor; $G n R H=$ gonadotropin releasing hormone; $H S L=$ hormone sensitive lipase; $I L=i n t e r l e u k i n ; L H=I$ I $L P L=$ lipoprotein lipase; $L P S=$ lipopolysaccharide; OSA = obstructive sleep apnoea; SHBG = sex hormone binding globulin; TG = triglyceride; $T$ NF = tumor necrosis factor.

4. Secondary hypogonadism: low or inappropriately normal LH or FSH.

5. Functional hypogonadism: other causes of hypogonadism excluded systematically.

Diagnostic recommendations based on British Society for Sexual Medicine guidelines are shown in Table $1 .^{50}$

\section{Management options}

Weight loss achieved using healthy lifestyle changes MOSH is a potentially reversible cause of HPT axis suppression and testosterone deficiency (functional hypogonadism) and hence can be managed with lifestyle measures to achieve significant weight loss, without the need for testosterone treatment..$^{51}$ Longitudinal data from the EMAS showed that weight loss can increase testosterone levels in obese men. Over a period of 4.4 years, minor weight loss (<15\%) was associated with a modest increase in TT levels $(2 \mathrm{nmol} / \mathrm{L}$ or $58 \mathrm{ng} / \mathrm{dL})$ and increases in SHBG (due to improvement in insulin resistance). However, there was no increase in FT levels with this degree of weight loss. Weight loss greater than $15 \%$ was associated with more marked increases in $\mathrm{TT}(5.7 \mathrm{nmol} / \mathrm{L}$ or $164 \mathrm{ng} / \mathrm{dL}$ ) and FT (52 pmol/L or $52 \mathrm{pg} / \mathrm{mL}$ ). The rise in testosterone level is proportional to the extent of weight loss achieved. ${ }^{52}$

Weight loss achieved by lifestyle modification can improve erectile dysfunction as measured by International Index of Erectile Function (IIEF). A randomised controlled trial (RCT) in relatively healthy obese men without diabetes, hypertension and dyslipidaemia showed that intensive lifestyle modification achieved a $15 \%$ weight loss and improved IIEF score by $3.1 .{ }^{53} \mathrm{~A}$ meta-analysis of four RCTs on obese men with cardiovascular risk factors demonstrated that lifestyle modification along with pharmacological treatment of cardiovascular risk factors resulted in an IIEF score improvement of 2.66. ${ }^{54}$ The Look AHEAD trial, which evaluated the effect of weight loss in older overweight/obese diabetic men, found that IIEF improved only by 1.3, probably due to increased frequency of irreversible neurovascular disease..$^{55}$

\section{Diet alone}

A recent study in patients with MOSH concluded that customised diet therapy with low-calorie, high-protein diet with personalised dietary counselling, and physical activity can induce positive changes in hormonal profile and body composition by increasing testosterone levels, decreasing oestradiol levels and by reducing the total fat mass. ${ }^{56}$ Improvements in dietary pattern (less eating out, minimal dairy products and desserts, enhanced consumption of dark green vegetables etc.) may help to prevent obesity associated testosterone deficiency.7

\section{Exercise alone}

Exercise can increase LH and testosterone production (via antiinflammatory effects on the hypothalamus and testes), and can recover erectile function in patients with MOSH. ${ }^{58}$ Aerobic exercises do improve testosterone levels whereas resistance exercises do not have a significant effect.59,60 Moreover, in patients on testosterone replacement therapy (TRT), exercise can augment the effects of TRT and the durability 
Table 1: Recommendations for the diagnosis and management of testosterone deficiency ${ }^{50}$

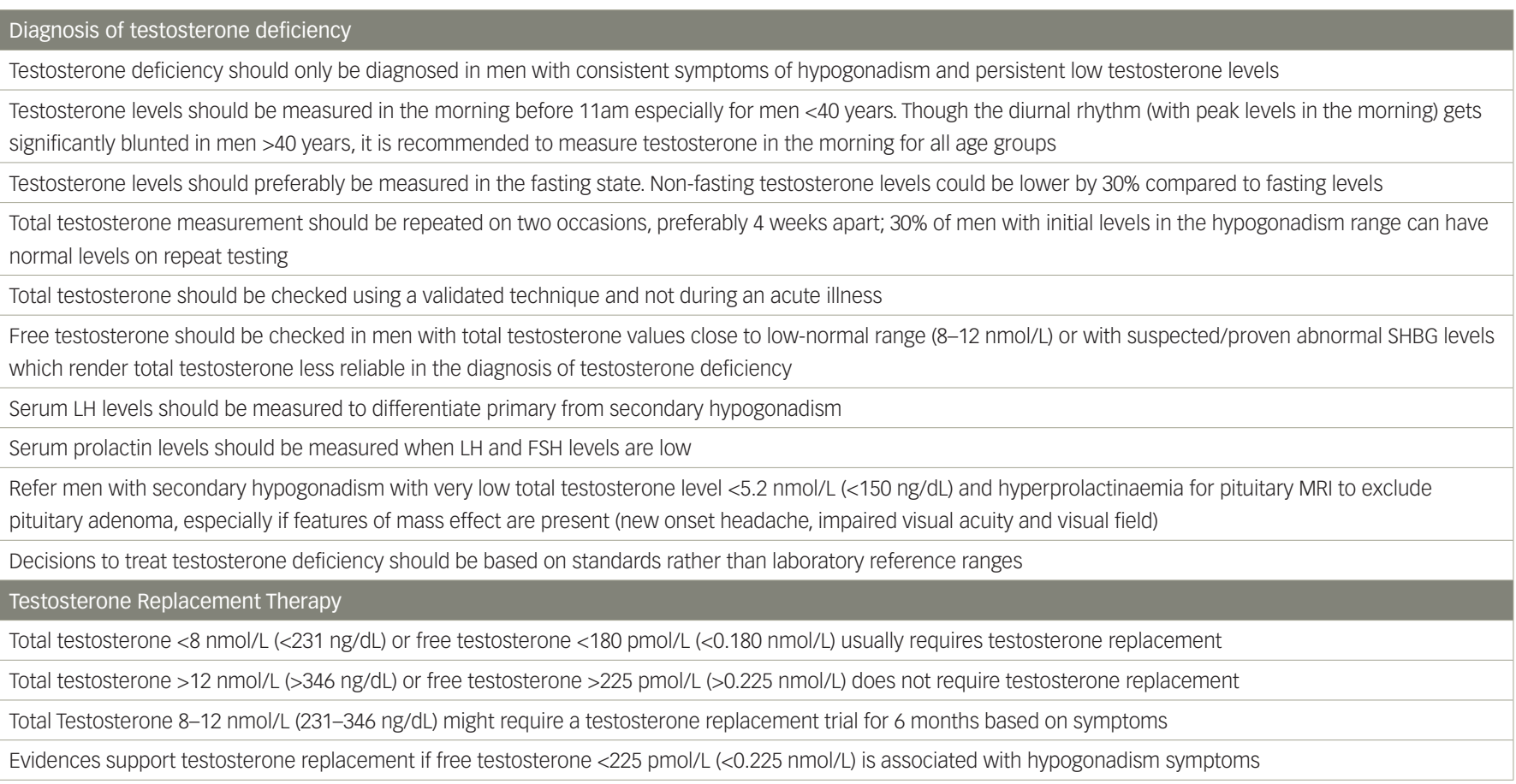

$F S H=$ follicle stimulating hormone; $L H=$ luteinising hormone; $M R I=$ magnetic resonance imaging; $S H B G=$ sex hormone binding globulin.

of response after cessation of TRT. ${ }^{61}$ Testosterone deficiency in obese men is associated with reduced physical activity, sarcopenia, decreased BMD and visceral obesity. ${ }^{62}$ Moderate aerobic exercise has been found to reverse all these parameters, reduce body weight by $5.9 \mathrm{~kg}$ and improve IIEF score by 2.6. ${ }^{62,63}$ Hence it is recommended that obese physically inactive men with multiple cardiovascular risk factors should undertake supervised physical training that consists of 40 minutes of moderate-tovigorous intensity aerobic exercise, at least 4 times per week. In general, weekly exercise of 160 minutes for 6 months can improve erectile function in obese physically inactive men. ${ }^{64}$

\section{Weight loss by treatment with liraglutide}

Glucagon like peptide-1 (GLP-1) receptor agonist, liraglutide, is approved as an adjunct in weight management, alongside dietary measures and increased physical activity, in individuals with a $\mathrm{BMl} \geq 30 \mathrm{~kg} / \mathrm{m}^{2}$ or in individuals with a $\mathrm{BMl} \geq 27 \mathrm{~kg} / \mathrm{m}^{2}$ and comorbidities such as type 2 diabetes mellitus (T2DM). A recent prospective randomised study comparing liraglutide and TRT in obese hypogonadal men, found that liraglutide treatment resulted in a significant increase of $\mathrm{LH}$ and FSH along with an average weight loss of $7.9 \pm 3.8 \mathrm{~kg}$ compared with a $0.9 \pm 4.5 \mathrm{~kg}$ loss with TRT $(p<0.001) .{ }^{65}$ Recovery of metabolic syndrome was observed in two patients on liraglutide whereas no subjects recovered from metabolic syndrome while on TRT. The study concluded that following failure of lifestyle modification, liraglutide is superior to TRT in men with obesity associated functional hypogonadism.

\section{Weight loss with bariatric surgery}

Though both lifestyle modification and bariatric surgery can achieve weight loss with a resultant rise in $\mathrm{TT}$ and $\mathrm{FT}$ levels, bariatric surgery is more effective in achieving weight loss than a low-calorie diet. Lifestyle modification resulted in a mean weight loss of $9.8 \%$ with an increase in $\mathrm{TT}$ of $2.87 \mathrm{nmol} / \mathrm{L}(84 \mathrm{ng} / \mathrm{dL})$ whereas bariatric surgery achieved a mean weight loss of $32 \%$ with an increase in TT of 8.73 (251 ng/ $\mathrm{dL}){ }^{66}$ The rise in $T \mathrm{~T}$ was greater in younger, non-diabetic subjects with higher baseline BMI, and in subjects who had lost the most weight. The best determinant of testosterone rise was the degree of weight loss. Weight loss was also associated with a rise in gonadotropin and fall in oestradiol levels. ${ }^{66}$

A recent study that directly compared laparoscopic gastric bypass (LGB) to restrictive bariatric surgical procedures in terms of testosterone level improvement found that both procedures are equally effective in achieving remission of MOSH. ${ }^{67} \mathrm{TT}$ and SHBG levels increase soon after bariatric surgery, at 1 month (due to improvements in insulin resistance), whereas FT levels do not increase until 6 months after bariatric surgery. Consequently, the improvements in symptoms of hypogonadism will only be observed after 6 months following surgery. ${ }^{68}$

Weight loss achieved by bariatric surgery is associated with improvements in sexual function and quality of life. In a recent metaanalysis, obese men who underwent bariatric surgery exhibited an increase in IIEF-5 score of 4.1-5.66..$^{69}$ The improvement in sexual function after bariatric surgery not only depends on testosterone levels, but also on degree of weight loss, the psychological impact of improved body image and baseline erectile function. ${ }^{70}$

\section{Testosterone replacement therapy}

obese men with secondary hypogonadism achieved a statistically significant reduction in fat mass $(3.5 \mathrm{~kg}, \mathrm{p}=0.03)$, increase in lean body mass $(2.9 \mathrm{~kg}, \mathrm{p}=0.03)$ and glycated haemoglobin ( $\mathrm{HbA} 1 \mathrm{C})$ improvement $(9 \mathrm{mmol} / \mathrm{mol}, \mathrm{p}=0.03)$, associated with $52 \%$ improvement in beta-cell function with TRT. ${ }^{71}$ Treatment also resulted in an overall improvement in metabolic state, including improvements in the following parameters: BMI, waist circumference, lipid profile, blood pressure, lipoprotein (a), haemoglobin, fasting glycaemia, insulin resistance and leptin resistance. ${ }^{72-78}$ TRT also reduced arterial stiffness, respiratory quotient, hepatic fat content and bone remodelling. ${ }^{79,80}$ TRT mediated and psychotropic effects included improved energy and motivation. ${ }^{81}$ 
Weight loss associated with TRT was almost exclusively due to loss of fat mass, whereas the weight loss due to dieting is from loss of both fat mass and lean mass. Although TRT did not augment diet-induced loss of fat mass, it prevented diet-induced loss of muscle mass. ${ }^{82}$ These favourable effects of TRT on body composition may be due to androgen receptor signalling in adipocytes and myocytes and/or increased physical activity seen in testosterone replaced men. However, successful visceral fat loss achieved by testosterone therapy is not maintained after cessation of TRT, as low testosterone (after TRT withdrawal) may lead to fatigue and inertia and less physical activity. ${ }^{83,84}$ This suggests that long term TRT is required to maintain the beneficial effects.

In obese healthy men with mild-to-moderate androgen deficiency symptoms and moderate testosterone deficiency, the improvement in androgen deficiency symptoms achieved with TRT is over and above what is achieved with weight loss alone, with the greatest benefits observed in severely symptomatic men. ${ }^{85} \mathrm{~A}$ recent meta-analysis found that TRT significantly improves erectile dysfunction in men with testosterone deficiency and improves the mean IIEF-5 scores by 1.47 and 2.95 for men with baseline testosterone levels of $<12 \mathrm{nmol} / \mathrm{l}$ and $<8 \mathrm{nmol} / \mathrm{l}$, respectively. 86

In obese hypogonadal men, irrespective of the class of obesity, TRT is effective in achieving and maintaining weight loss. ${ }^{87}$ Hypogonadal men on long-acting intramuscular testosterone undecanoate achieved 5\% weight loss in 1 year and $13 \%$ weight loss in 5 years. ${ }^{88}$ Two meta-analyses of five and eight RCTs concluded that TRT can significantly improve glycaemic control along with a reduction in triglycerides in type 2 diabetic hypogonadal men. ${ }^{89,90}$ However, a third meta-analysis of seven RCTs failed to demonstrate any significant improvement in glycaemic control, which implies that TRT does not have a consistent effect on HDA1C. ${ }^{91}$

Due to conflicting evidences relating TRT to cardiovascular disease (CVD) and mortality, the US Food and Drug Administration has warned that TRT might increase heart attack and stroke. A critical review of all the published systematic reviews found that two out of six systematic reviews and metaanalyses showed increased CVD risk with TRT. ${ }^{92}$ However, recent reviews shows that there is a trend towards reduced major adverse cardiac events, all cause and cardiovascular mortality with TRT, with the greatest benefit seen in men at highest risk of CVD, such as those with T2DM and metabolic syndrome. ${ }^{93}$ Moreover, greater benefits are observed among those treated to the target and for longer duration. ${ }^{94}$ A recently published populationbased observational study showed that longer duration TRT is associated with decreased mortality, CVD events and prostate cancer, whereas shorter duration TRT increased mortality and CVD events. ${ }^{95}$

\section{Selective oestrogen receptor modulators}

TRT can cause suppression of spermatogenesis and testicular atrophy and is not the best option for young men with hypogonadism who desire fertility preservation. Clomiphene citrate is a selective oestrogen receptor modulator which is effective in stimulating the HPT axis and normalising the hormonal profile without causing testicular atrophy. A recent study evaluating the effect of clomiphene citrate in adult men with MOSH found an improvement of hypogonadal symptoms (associated with increases in TT, FT, LH, FSH, and SHBG) and improvements in lean mass, fat-free mass, and muscle mass in the clomiphene treated cohort. Investigators concluded that clomiphene citrate may be used as an alternative treatment for MOSH in adult men. ${ }^{96}$ However, selective oestrogen receptor modulators may reduce insulin-like growth factor-1 (IGF-1) levels with a resultant reduction in anabolism, and an increase in SHBG levels that reduce testosterone bioavailability. ${ }^{97}$

\section{Aromatase inhibitors}

In elderly obese men with hypogonadism, administration of anastrozole, an oral aromatase inhibitor, increased androgen levels and decreased oestradiol levels but without any improvement in body composition, strength or lipid levels. ${ }^{98}$ Despite a significant rise in testosterone levels, the use of an aromatase inhibitor is not associated with any somatic or psychological effects in obese men with hypogonadism and is associated with worsening of spinal BMD. ${ }^{99,100}$ Due to the worsening of BMD and lack of body composition improvement, aromatase inhibitors are not an ideal alternative to TRT in obese hypogonadal men.

\section{When to consider organic hypothalamo- pituitary-testicular axis suppression in an obese male}

Young healthy men, without comorbidities, with typical androgen deficiency symptoms and unequivocally low testosterone should be considered to have organic hypogonadism. In men with suspected MOSH, lifestyle modification, including weight reduction, optimal treatment of diabetes and other comorbidities, should comprise first-line treatment of the condition. If these measures fail to normalise the androgen deficiency symptoms and/or low testosterone levels, despite successful weight loss, clinicians should repeat evaluations to rule out organic HPT axis suppression. ${ }^{101}$ Once this has been ruled out, a therapeutic trial of TRT can be considered in those with severe androgen deficiency symptoms and unequivocally low testosterone levels, unless contraindicated.

\section{Areas of uncertainty}

\section{Effect of testosterone on HbA1c}

TRT does not consistently affect HDA1C in obese men with diabetes. ${ }^{89-91}$ It is possible that increased erythropoiesis, which occurs as a side effect of TRT, may affect HbA1c independently of changes in glycaemia. Hence, studies with careful analysis of self-monitored blood glucose data and alternative measures of glycaemia other than HbA1c should be designed to evaluate the effect of testosterone on $\mathrm{HbA} 1 \mathrm{C}$.

\section{Effect of testosterone on subcutaneous adipose tissue and visceral adipose tissue}

Visceral adipose tissue is more strongly linked to insulin resistance than subcutaneous adipose tissue is. Though various RCTs have consistently proved that TRT can reduce total body fat mass, ${ }^{77,82-83,102-103}$ its effects on regional fat redistribution are not consistently proven; some studies have shown a reduction in visceral adipose tissue ${ }^{103-104}$ whereas others have not. ${ }^{79,102,105}$ These inconsistencies may be due to small sample sizes or imprecise methodology to quantify visceral adipose tissue like dualenergy X-ray absorptiometry or ultrasound.

\section{Indications for testosterone replacement therapy in} male obesity-related secondary hypogonadism

Testosterone therapy should only be prescribed for those with clinically significant symptoms with persistently low testosterone levels. TRT should not be routinely prescribed to men with functional hypogonadism, including MOSH, and low-normal testosterone until clinical benefit is confirmed by well-powered clinical trials.

\section{Testosterone replacement therapy and cardiovascular disease risk}

Earlier studies suggested that TRT might increase CVD risk.92 However, many recent studies showed reduced CVD risk and all-cause mortality with TRT in hypogonadal men with long term treatment.93-94 This safety matter requires further investigation in large-scale prospective RCTs that focus on the cardiovascular benefits and risks associated with TRT. 


\section{Summary and conclusions}

With the increasing prevalence of obesity, the incidence of MOSH is also increasing. ${ }^{106}$ Lifestyle modification remains the first-line management of MOSH as this improves the overall health of the patient and has the potential to improve androgen deficiency symptoms irrespective of any effect on testosterone levels. In selected patients with clinical indications, weight loss interventions such as bariatric surgery can revert the hypogonadotrophic hypogonadism caused by obesity. If these measures fail to relieve symptoms and to normalise testosterone levels, in appropriately selected men, TRT could be started. Other medications such as aromatase inhibitors and selective oestrogen receptor modulators are not recommended due to lack of clinical trial-based evidence. $\square$
1. World Health Organization. Obesity and overweight, 2018 Available at: www.who.int/news-room/fact-sheets/detail/ obesity-and-overweight (accessed 09 July 2019).

2. Saboor-Aftab SA, Kumar S, Barber TM. The role of obesity and type 2 diabetes mellitus in the development of male obesity-associated secondary hypogonadism. Clin Endocrinol (Oxf). 2013;78:330-7.

3. Kelly DM, Jones TH. Testosterone and obesity. Obes Rev. 2015;16:581-606.

4. Calderón B, Gómez-Martín JM, Vega-Piñero B, et al. Prevalence of male secondary hypogonadism in moderate to severe obesity and its relationship with insulin resistance and excess body weight. Andrology. 2016;4:62-7.

5. Hofstra J, Loves S, van Wageningen B, et al. High prevalence of hypogonadotropic hypogonadism in men referred for obesity treatment. Neth J Med. 2008;66:103-9.

6. Antonio L, WU FC, O'Neill TW, et al. Low free testosterone is associated with hypogonadal signs and symptoms in men with normal total testosterone. I Clin Endocrinol Metab. 2016;101:2647-57.

7. Anderson JL, May HT, Lappé DL, et al. Impact of testosterone replacement therapy on myocardial infarction, stroke, and death in men with low testosterone concentrations in an integrated health care system. Am J Cardiol. 2016;117:794-9.

8. Iglesias P, Prado F, Ridruejo E, et al. Hypogonadism and mortality in aged hospitalized male patients: A 5-year prospective observational study. Exp Clin Endocrinol Diabetes. 2015;123:589-93.

9. Pye SR, Huhtaniemi IT, Finn JD, et al. Late-onset hypogonadism and mortality in aging men. J Clin Endocrinol Metab. 2014;99:1357-66.

10. Rao PM, Kelly DM, Jones TH. Testosterone and insulin resistance in the metabolic syndrome and T2DM in men. Nat Rev Endocrinol. 2013;9(8):479-93.

11. Tajar A, Forti G, O'Neill TW, et al. Characteristics of secondary, primary, and compensated hypogonadism in aging men: evidence from the European male ageing study J Clin Endocrinol Metab. 2010;95:1810-18.

12. Tsai EC, Boyko EJ, Leonetti DL, et al. Low serum testosterone level as a predictor of increased visceral fat in JapaneseAmerican men. Int J Obes Relat Metab Disord. 2000;24:485-91.

13. Georgiev IP, Georgieva TM, Ivanov V, et al. Effects of castrationinduced visceral obesity and antioxidant treatment on lipid profile and insulin sensitivity in New Zealand white rabbits. Res Vet Sci. 2011;90:196-204

14. Saylor PJ, Smith MR. Metabolic complications of androgen deprivation therapy for prostate cancer. J Urol. 2013;189:S34-42.

15. Wang $\mathrm{N}$, Zhai $\mathrm{H}$, Han $\mathrm{B}$, et al. Visceral fat dysfunction is positively associated with hypogonadism in Chinese men Sci Rep. 2016;6:19844.

16. Haymana C, Sonmez A, Aydogdu A, et al. Visceral adiposity index and triglyceride/high-density lipoprotein cholesterol ratio in hypogonadism. Arch Endocrinol Metab. 2017;61:282-7.

17. Jensterle M, Podbregar A, Goricar K, et al. Effects of liraglutide on obesity-associated functional hypogonadism in men. Endocr Connect. 2019;8:195-202.

18. Escobar-Morreale HF, Santacruz E, Luque-Ramirez M, et al. Prevalence of 'obesity-associated gonadal dysfunction' in severely obese men and women and its resolution after bariatric surgery: a systematic review and meta-analysis. bariatric surgery: a systematic review
Hum Reprod Update. 2017;23:390-408.

19. Pellitero $S$, Olaizola I, Alastrue $A$, et al. Hypogonadotropic hypogonadism in morbidly obese males is reversed after bariatric surgery. Obes Surg. 2012;22:1835-42.

20. Corona G, Rastrelli G, Monami M, et al. Body weight loss reverts obesity-associated hypogonadotropic hypogonadism: a systematic review and meta-analysis. Eur J Endocrinol. 2013;168:829-43.

21. Brand JS, van der Tweel I, Grobbee DE, et al. Testosterone, sex hormone-binding globulin and the metabolic syndrome: a systematic review and meta-analysis of observational studies. Int J Epidemiol. 2011;40:189-207.

22. Garcia-Cruz E, Piqueras M, Huguet J, et al. Hypertension, dyslipidemia and overweight are related to lower testosterone levels in a cohort of men undergoing prostate biopsy. Int $\rfloor$ Impot Res. 2012:24:110-3.

23. O'Reilly MW, Glisic M, Kumarendran B, et al. Serum testosterone, sex hormone-binding globulin and sex-specific risk of incident type 2 diabetes in a retrospective primary care cohort. Clin Endocrinol (Oxf). 2018;90:145-5

24. Bhasin S, Jasjua GK, Pencina M, et al. Sex hormone-binding globulin, but not testosterone, is associated prospectively and independently with incident metabolic syndrome in men: the Framingham heart study. Diabetes Care. 2011:34:2464-70.

25. Tripathy D, Dhindsa S, Garg R, et al. Hypogonadotropic hypogonadism in erectile dysfunction associated with type 2 diabetes mellitus: a common defect? Metab Syndr Relat Disord. 2003;1:75-80

26. Cohen PG. The hypogonadal-obesity cycle: role of aromatase in modulating the testosterone-estradiol shunt--a major factor in the genesis of morbid obesity. Med Hypotheses. 1999:52:49-51.

27. Laaksonen DE, Niskanen L, Punnonen K, et al. The metabolic syndrome and smoking in relation to hypogonadism in middle-aged men: a prospective cohort study. I Clin Endocrinol Metab. 2005;90:712-9.

28. Kelly DM, Jones TH. Testosterone: a metabolic hormone in health and disease. J Endocrinol. 2013;217:R25-45.

29. Singh R, Artaza JN, Taylor WE, et al. Androgens stimulate myogenic differentiation and inhibit adipogenesis in $\mathrm{C} 3 \mathrm{H}$ 10T1/2 pluripotent cells through an androgen receptormediated pathway. Endocrinology. 2003;144:5081-8.

30. Bianchi VE. The anti-inflammatory effects of testosterone J Endocr Soc. 2018:3:91-107.

31. Rasouli N, Kern PA. Adipocytokines and the metabolic complications of obesity. J Clin Endocrinol Metab. 2008:93:S64-73.

32. McArdle MA, Finucane OM, Connaughton RM, et al. Mechanisms of obesity-induced inflammation and insulin resistance: insights into the emerging role of nutritiona strategies. Front Endocrinol (Lausanne). 2013;4:52.

33. Sarchielli E, Comeglio P, Squecco R, et al. Tumor Necrosis Factor- $\alpha$ impairs kisspeptin signalling in human gonadotropinreleasing hormone primary neurons. J Clin Endocrinol Metab. 2017;102:46-56

34. Morelli A, Sarchielli E, Comeglio P, et al. Metabolic syndrome induces inflammation and impairs gonadotropin-releasing hormone neurons in the preoptic area of the hypothalamus in rabbits. Mol Cell Endocrinol. 2014;382:107-19.

35. Grossmann M. Testosterone and glucose metabolism in men: current concepts and controversies. J Endocrinol. 2014;220:R37-55

36. Pitteloud N, Mootha VK, Dwyer AA, et al. Relationship between testosterone levels, insulin sensitivity, and mitochondrial function in men. Diabetes Care. 2005;28:1636-42.

37. Clarke H, Dhillo WS, Jayasena CN. Comprehensive review on kisspeptin and its role in reproductive disorders. Endocrinol Metab (Seoul). 2015;30:124-41.

38. George JT, Millar RP, Anderson RA. Hypothesis: kisspeptin mediates male hypogonadism in obesity and type 2 diabetes. Neuroendocrinology. 2010;91:302-7.

39. Sanchez-Garrido MA, Ruiz-Pino F, Manfredi-Lozano M, et al. Obesity-induced hypogonadism in the male: premature reproductive neuroendocrine senescence and contribution of Kiss1-mediated mechanisms. Endocrinology. 2014:155:1067-79.

40. Harter CJL, Kavanagh GS, Smith JT. The role of kisspeptin neurons in reproduction and metabolism. J Endocrinol. 2018:238:R173-R183

41. Caprio M, Isidori AM, Carta AR, et al. Expression of functional leptin receptors in rodent Leydig cells. Endocrinology. 1999;140:4939-47.

42. Isidori AM, Caprio M, Strollo F, et al. Leptin and androgens in male obesity: evidence for leptin contribution to reduced androgen levels. J Clin Endocrinol Metab. 1999;84:3673-80.

43. Roseweir AK, Millar RP. The role of kisspeptin in the control of gonadotrophin secretion. Hum Reprod Update. 2009;15:203-12.

44. Quennell JH, Mulligan AC, Tups A, et al. Leptin indirectly regulates gonadotropin-releasing hormone neuronal function Endocrinology. 2009:150:2805-12.

45. Tremellen K, McPhee N, Pearce K, et al. Endotoxin-initiated inflammation reduces testosterone production in men of reproductive age. Am J Physiol Endocrinol Metab. 2018:314:E206-E213.

46. Goldman AL, Bhasin S, Wu FCW, et al. A reappraisal of testosterone's binding in circulation: physiological and clinical implications. Endocr Rev. 2017;38:302-24

47. Yamazaki H, Kushiyama A, Sakoda H, et al. Protective effect of sex hormone-binding globulin against metabolic syndrome: in vitro evidence showing anti-inflammatory and lipolytic effects on adipocytes and macrophages. Mediators Inflamm. 2018;2018:3062319.

48. Kim SD, Cho KS. Obstructive sleep apnea and testosterone deficiency. World I Mens Health 2019:37:12-8.

49. Wu FC, Tajar A, Beynon JM, et al; EMAS Group. Identification of late-onset hypogonadism in middle-aged and elderly men. N Engl I Med. 2010;363:123-35.

50. Hackett G, Kirby M, Edwards D, et al. British society for sexual medicine guidelines on adult testosterone deficiency, with statements for UK practice. I Sex Med 2017:14:1504-23.

51. Bhasin S, Brito JP, Cunningham GR, et al. Testosterone therapy in men with hypogonadism: an endocrine society clinical practice guideline. J Clin Endocrinol Metab. 2018;103:1715-44

52. Camacho EM, Huhtaniemi IT, O'Neill TW, et al; EMAS Group Age-associated changes in hypothalamic-pituitary-testicula function in middle-aged and older men are modified by weight change and lifestyle factors: Iongitudinal results from the European Male Ageing Study. Eur J Endocrinol. 2013;168:445-55

53. Esposito K, Giugliano F, Di Palo C, et al. Effect of lifestyle changes on erectile dysfunction in obese men: a randomized controlled trial. JAMA. 2004;291:2978-84.

54. Gupta BP, Murad MH, Clifton MM, et al. The effect of lifestyle modification and cardiovascular risk factor reduction on erectile dysfunction: a systematic review and meta-analysis. Arch Intern Med 2011:171:1797-803.

55. Wing RR, Rosen RC, Fava JL, et al. Effects of weight loss

intervention on erectile function in older men with type 2 diabetes in the Look AHEAD trial. J Sex Med. 2010;7:156-65.

56. De Lorenzo A, Noce A, Moriconi E, et al. MOSH syndrome (male obesity secondary hypogonadism): clinical assessment and possible therapeutic approaches. Nutrients. 2018;10(4).pii:E474

57. Hu TY, Chen YC, Lin P, et al. Testosterone-associated dietary pattern predicts low testosterone levels and hypogonadism. Nutrients. 2018;10(11).pii:E1786.

58. Morelli A, Filippi S, Comeglio P, et al. Physical activity counteracts metabolic syndrome-induced hypogonadotropic hypogonadism and erectile dysfunction in the rabbit.

59. Yeo JK, Cho SI, Park SG, et al. Which exercise is better for increasing serum testosterone levels in patients with erectile dysfunction? World I Mens Health. 2018; 36:147-52.

60. Hayes LD, Elliott BT. Short-term exercise training inconsistently influences basal testosterone in older men: a systematic review and meta-analysis. Front Physiol. 2019;9:1878

61. Cho DY, Yeo JK, Cho SI, et al. Exercise improves the effects of testosterone replacement therapy and the durability of response after cessation of treatment: a pilot randomized controlled trial. Asian J Androl. 2017;19:602-7.

62. Villareal DT, Chode S, Parimi N, Sinacore et al. Weight loss, exercise, or both and physical function in obese older adults. N Engl J Med. 2011;364:1218-29.

63. Khoo J, Tian HH, Tan B, et al. Comparing effects of low- and high-volume moderate-intensity exercise on sexual function and testosterone in obese men. I Sex Med 2013:10:1823-32.

64. Gerbild H, Larsen CM, Graugaard C, et al. Physical activity to improve erectile function: A systematic review of intervention studies. Sex Med. 2018;6:75-89.

65. Jensterle M, Podbregar A, Goricar K, et al. Effects of liraglutide on obesity-associated functional hypogonadism in men. Endocr Connect. 2019;8:195-202.

66. Corona G, Rastrelli G, Monami M, et al. Body weight loss reverts obesity-associated hypogonadotropic hypogonadism: a systematic review and meta-analysis. Eur J Endocrinol. 2013;168:829-43.

67. Calderon B, Galdon A, Calanas A, et al. Effects of bariatric surgery on male obesity-associated secondary hypogonadism: comparison of laparoscopic gastric bypass with restrictive procedures. Obes Surg. 2014;24:1686-92.

68. Boonchaya-Anant $P$, Laichuthai $N$, Suwannasrisuk $P$, et al. Changes in testosterone levels and sex hormone-binding globulin levels in extremely obese men after bariatric surgery. Int J Endocrinol. 2016;2016:1416503.

69. Glina FPA, de Freitas-Barboza JW, Nunes VM, et al. What is the impact of bariatric surgery on erectile function? A systematic review and meta-analysis. Sex Med Rev. 2017;5:393-402.

70. Mora M, Aranda GB, de Hollanda A, et al. Weight loss is a major contributor to improved sexual function after bariatric surgery. Surg Endosc. 2013;27:3197-204.

71. Dimitriadis GK, Randeva HS, Aftab S, et al. Metabolic phenotype of male obesity-related secondary hypogonadism pre-replacement and post-replacement therapy with intramuscular testosterone undecanoate therapy. Endocrine. 2018;60:175-84

72. Haider A, Saad F, Doros $G$, et al. Hypogonadal obese men with and without diabetes mellitus type 2 lose weight and show improvement in cardiovascular risk factors when treated with testosterone: an observational study. Obes Res Clin Pract. 2014;8:e339-49

73. Francomano D, Lenzi A, Aversa A. Effects of five-year treatment with testosterone undecanoate on metabolic and hormonal parameters in ageing men with metabolic syndrome Int J Endocrinol. 2014;2014:527470.

74. Jones TH, Arver S, Behre HM, et al; TIMES2 Investigators. Testosterone replacement in hypogonadal men with type 2 diabetes and/or metabolic syndrome (the TIMES2 study). Diabetes Care. 2011;34:828-37.

75. Dhindsa S, Ghanim H, Batra M, et al. Hypogonadotropic hypogonadism in men with diabesity. Diabetes Care. 2018:41:1516-25

76. Kapoor D, Goodwin E, Channer KS, et al. Testosterone replacement therapy improves insulin resistance, glycaemic control, visceral adiposity and hypercholesterolaemia in hypogonadal men with type 2 diabetes. Eur J Endocrinol. 2006; 154:899-906

77. Corona G, Giagulli VA, Maseroli E, et al. Therapy of endocrine disease: Testosterone supplementation and body composition: results from a meta-analysis study. Eur $J$ Endocrinol. 2016;174:R99-116

78. Ng Tang Fui M, Hoermann R, Grossmann M. Effect of testosterone treatment on adipokines and gut hormones in obese men on a hypocaloric diet. J Endocr SOC. 2017;1:302-12.

79. Hoyos CM, Yee BJ, Phillips CL, et al. Body compositional and cardiometabolic effects of testosterone therapy in obese men with severe obstructive sleep apnoea: a randomised placebo-controlled trial. Eur J Endocrinol. 2012;167:531-41.

80. Ng Tang Fui M, Hoermann R, Nolan B, et al. Effect of testosterone treatment on bone remodelling markers and mineral density in obese dieting men in a randomized clinical 
trial. Sci Rep. 2018;8:9099.

81. Saad F, Aversa A, Isidori AM, et al. Testosterone as potential effective therapy in treatment of obesity in men with testosterone deficiency: a review. Curr Diabetes Rev. 2012;8:131-43.

82. Ng Tang Fui M, Prendergast $L A$, Dupuis $P$, et al. Effects of testosterone treatment on body fat and lean mass in obese men on a hypocaloric diet: a randomised controlled trial. BMC Med. 2016;14:153.

83. Ng Tang Fui M, Hoermann R, Zajac JD, et al. The effects of testosterone on body composition in obese men are not sustained after cessation of testosterone treatment. Clin Endocrinol (Oxf). 2017;87:336-43.

84. O'Connor DB, Archer J, WU FC. Effects of testosterone on mood, aggression, and sexual behaviour in young men: a double-blind, placebo-controlled, cross-over study. J Clin Endocrinol Metab. 2004;89:2837-45.

85. Ng Tang Fui M, Hoermann R, Prendergast LA, et al. Symptomatic response to testosterone treatment in dieting obese men with low testosterone levels in a randomized, placebo-controlled clinical trial. Int J Obes (Lond). 2017:41:420-6.

86. Corona $G$, Rastrelli G, Morgentaler A, et al. Meta-analysis of results of testosterone therapy on sexual function based on international index of erectile function scores. Eur Urol. 2017:72:1000-11

87. Saad F, Yassin A, Doros G, et al. Effects of long-term treatment with testosterone on weight and waist size in 411 hypogonada men with obesity classes I-III: observational data from two registry studies. Int J Obes (Lond). 2016;40:162-70.

88. Saad F, Haider A, Doros G, et al. Long-term treatment of hypogonadal men with testosterone produces substantial and sustained weight loss Obesity (Silver Spring). 2013:21:1975-81.

89. Cai X, Tian Y, Wu T, et al. Metabolic effects of testosterone

replacement therapy on hypogonadal men with type 2 diabetes mellitus: a systematic review and meta-analysis of randomized controlled trials. Asian J Androl. 2014;16:146-52.

90. Zhang J, Yang B, Xiao W, et al. Effects of testosterone supplement treatment in hypogonadal adult males with T2D : a meta-analysis and systematic review. World J Uro 2018;36:1315-26.

1. Grossmann M, Hoermann R, Wittert G, et al. Effects of testosterone treatment on glucose metabolism and symptom in men with type 2 diabetes and the metabolic syndrome: systematic review and meta-analysis of randomized controlled clinical trials. Clin Endocrinol (OXf). 2015;83:344-51.

92. Onasanya O, lyer G, Lucas E, et al. Association between exogenous testosterone and cardiovascular events: an overview of systematic reviews. Lancet Diabetes Endocrinol. 2016;4:943-56.

93. Corona G, Maseroli E, Rastrelli G, et al. Cardiovascular risk associated with testosterone-boosting medications: a systematic review and meta-analysis. Expert Opin Drug Saf. 2014;13:1327-51.

94. Hackett $\mathrm{G}$. Metabolic effects of testosterone therapy in men with type 2 diabetes and metabolic syndrome. Sex Med Rev. with type 2 diabete

95. Wallis CJ, Lo K, Lee Y, et al. Survival and cardiovascular events in men treated with testosterone replacement therapy: an intention-to-treat observational cohort study. Lancet Diabetes Endocrinol. 2016;4:498-506.

96. Soares AH, Horie NC, Chiang LAP, et al. Effects of clomiphene citrate on male obesity-associated hypogonadism: a randomized, double-blind, placebo-controlled study. Int $\mathrm{J}$ Obes (Lond). 2018;42:953-63.

97. Birzniece $V$, Sata A, Sutanto $S$, et al. Neuroendocrine regulation of growth hormone and androgen axes by selective estrogen receptor modulators in healthy men. J Clin Endocrinol Metab. 2010;95:5443-8.

98. Burnett-Bowie SA, Roupenian KC, Dere ME, et al. Effects of aromatase inhibition in hypogonadal older men: a randomized, double-blind, placebo-controlled trial. Clin Endocrinol (Oxf) 2009;70:116-23.

99. Loves S, de Jong J, van Sorge A, et al. Somatic and psychologica effects of low-dose aromatase inhibition in men with obesity-related hypogonadotropic hypotestosteronemia. Eur J Endocrinol. 2013;169:705-14.

100. Burnett-Bowie SA, McKay EA, Lee $H$, et al. Effects of aromatase inhibition on bone mineral density and bone turnover in olde men with low testosterone levels. J Clin Endocrinol Metab. 2009;94:4785-92.

101. Grossmann M, Matsumoto AM. A Perspective on middle-aged and older men with functional hypogonadism: focus on holistic management. J Clin Endocrinol Metab. 2017;102:1067-75.

102. Magnussen LV, Andersen PE, Diaz A, et al. MR spectroscopy of hepatic fat and adiponectin and leptin levels during testosterone therapy in type 2 diabetes: a randomized, double-blinded, placebo-controlled trial. Eur J Endocrinol. 2017;177:157-68.

103. Kalinchenko SY, Tishova YA, Mskhalaya GJ, et al. Effects of testosterone supplementation on markers of the metabolic syndrome and inflammation in hypogonadal metabolic syndrome and inflammation in hypogonada men with the metabolic syndrome: the double-binded placebo-controlled Moscow study. Clin Endocrinol (Oxf) 2010;73:602-12

104. Allan CA, Strauss BJ, Burger HG, et al. Testosterone therapy prevents gain in visceral adipose tissue and loss of skeleta muscle in nonobese aging men. $J$ Clin Endocrinol and Metab. 2008;93:139-46

105. Bhasin S, Parker RA, Sattler F, et al. Effects of testosterone supplementation on whole body and regional fat mass and distribution in human immunodeficiency virus-infected men with abdominal obesity I Clin Endocrinol Metab. 2007:92:1049-57.

106. Grossmann M. Hypogonadism and male obesity: Focus on unresolved questions. Clin Endocrinol (Oxf). 2018;89:11-21. 